\title{
Sol-gel processing and physic-chemical characterization of La and Ce doped lead titanate ceramics
}

\author{
Y. Guaaybess ${ }^{1}$, M. Maanan ${ }^{1}$, R. Adhiri ${ }^{1}$, M. Moussetad ${ }^{1}$, A. El Mesbahi², \\ S. Sayouri ${ }^{3}$ and L. Zarhouni ${ }^{1}$ \\ ${ }^{1}$ LEAMCM, Physic Department, Faculty of Sciences Ben M'sik, BP. 7955 Sidi Othmane, Casablanca, Morocco \\ ${ }^{2}$ Mechanical Engineering Department, FST Tanger, Morocco \\ ${ }^{3}$ LPTA, Physic Department, Faculty of Sciences Dhar Mhraz Fès, Morocco
}

\begin{abstract}
PbTiO}_{3}$ (PT) sol gel processed powders doped with lanthanum (PLT14) and cerium (PLCexT14, x = 1; 3; 6; 10) were characterized by XRD and Raman spectroscopy. The samples crystallize in a pure perovskite phase at temperatures smaller than those reported for the same compounds prepared by other conventional methods. The effect of cerium or/and lanthanum on the crystal structure, microstructural and dielectric properties of $\mathrm{PbTiO}_{3}$ were investigated using FTIR, XRD, SEM, Raman spectroscopy and impedance spectroscopy. Incorporation of Ce reduces the temperature of crystallization of the samples, the temperature of the maximum of the permittivity and the diffuseness character of the ferroelectric to paraelectric transition, and enhances the permittivity.
\end{abstract}

\section{INTRODUCTION}

Perovskite-type lead titanate, $\mathrm{PbTiO}_{3}(\mathrm{PT})$ of a general formula $\mathrm{ABO}_{3}\left(\mathrm{~A}=\mathrm{Pb}^{2+}, \mathrm{B}=\mathrm{Ti}^{4+}\right)$, is an important ferroelectric material which is characterized by remarkable ferroelectric, piezoelectric and pyroelectric properties. It is well know that PT possesses a high curie point $\left(\mathrm{T}_{c}\right)$ of $490^{\circ} \mathrm{C}$, and a large tetragonality of $\mathrm{c} / \mathrm{a}=1.064$. This large tetragonality results in a large stress within the lattice, therefore, it is difficult to prepare pure and dense PT ceramics. Lead lanthanum titanate, $\mathrm{Pb}_{1-\mathrm{x}} \mathrm{La}_{\mathrm{x}} \mathrm{Ti}_{1-\mathrm{x} / 4} \mathrm{O}_{3}$ (PLT), prepared by replacing a part of $\mathrm{Pb}$ by $\mathrm{La}$, has been considered as a physic-chemical modifier to PT ceramics. PLT with $\mathrm{x}=0.14$ is know to have a tetragonality close to 1.0 and improved dielectric properties [1].

Theses materials have been prepared using different methos, such as conventional solid, sol-gel, coprecipitation etc. Among them, sol-gel process, possessing some advantages; low processing temperature, high purity, chemical homogeneity and stoichiometry controls, etc. [1-3]. However, sol-gel was regarded as solid rather than solution process because solvents must be driven out of the system by high temperature calcination before the formation of the crystalline material [4].

In the present work, we have prepared, using the sol gel process, pure and doped $\mathrm{PbTiO}_{3}$ (PT). Doping was made with $14 \%$ of La (PLT14), and with 1, 3, 6 and $10 \%$ of $\mathrm{Ce}\left(\mathrm{PLCe}_{x} \mathrm{~T} 14, \mathrm{x}=0.01 ; 0.03 ; 0.06 ; 0.10\right)$. These samples were characterized by XRD, FTIR and Raman spectroscopy; SEM and dielectric measurements were performed using an HP impedance meter, and the effect of $\mathrm{Ce}$ on structural and dielectric properties of these samples was investigated.

\section{EXPERIMENTAL}

The following precursors were used to prepare the PLT powders: lead acetate $\left(\mathrm{Pb}\left(\mathrm{CH}_{3} \mathrm{COO}\right)_{2}, 3 \mathrm{H}_{2} \mathrm{O}\right.$, purity
99.9\%, Johnson Matthey GmbH Alfa, Karlsrube, Germany), lanthanum acetate $\left(\mathrm{La}\left(\mathrm{CH}_{3} \mathrm{COO}\right)_{3}, \mathrm{xH}_{2} \mathrm{O}\right)$ (purity 99.9\%, $\mathrm{x}=1.5$, Johnson Matthey GmbH Alfa, Karlsrube, Germany), titanium alcoxide (97\% (Assay) Johnson Matthey GmbH Alfa, Karlsrube, Germany). Bidistilled water was used as solvent. The flow diagram of Figure 1 gives the steps of the fabrication of PLCeT ceramics. Due to $\mathrm{Pb}$ loss during annealing process, 5 mol.\% excess lead acetate was added. Phase identification of the samples was performed using X-ray diffraction $(\mathrm{Cu} \mathrm{K} \alpha$ ray, $\lambda=1.5418 \AA$ ).

\section{RESULTS AND DISCUSSION}

FTIR spectra of the raw powders of PT, PLCe ${ }_{x}$ T14, with $\mathrm{x}=0 ; 0.03 ; 0.06$ and 0.10 , are shown in Figure 2. These spectra, which are similar, show a series of bands. The absorption band at $3400 \mathrm{~cm}^{-1}$ corresponds to the stretching of $\mathrm{OH}$ group. There exist two absorption bands at 1420 and $1569 \mathrm{~cm}^{-1}$ which are attributed to the asymmetric and asymmetric COO- stretching modes of the acetate groups. The separation wave number between those two stretching modes $(\Delta v)$ is a characteristic value, depending on the way carboxylate binds to the metal. If the $\Delta v$ value is less than $80 \mathrm{~cm}^{-1}$, acetate is typically a chelating bidentate ligand. Otherwise, as the $\Delta v$ is higher than $160 \mathrm{~cm}^{-1}$, acetate is typically a bridging bidentate ligand. The peaks around $1000 \mathrm{~cm}^{-1}$ indicate that carbonate is present in the dried gels.

Crystallization of these powders in the pure perovskite structure takes place at relatively low temperature, which is indicated, as illustration, by the presence, in the spectra corresponding to $\mathrm{PLCe}_{x} \mathrm{~T} 14(\mathrm{x}=0.10)$ heated at different temperatures, of the band around $550 \mathrm{~cm}^{-1}$. Indeed, the latter is the signature of the perovskite phase. These observations are confirmed by XRD performed on these samples as shown below. 


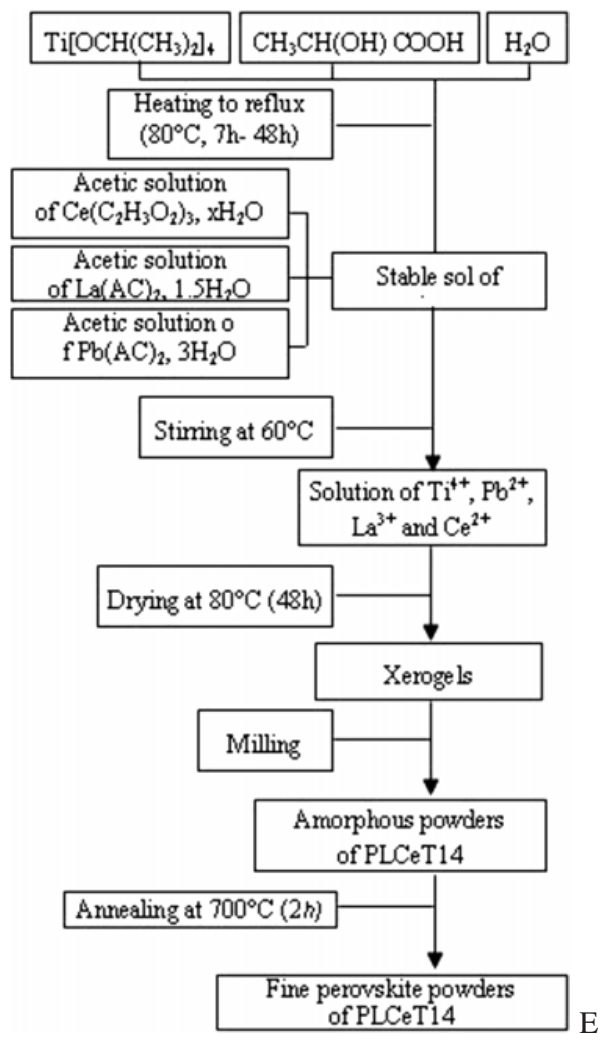

Figure 1. Flow chart of the preparation of PLT powders.

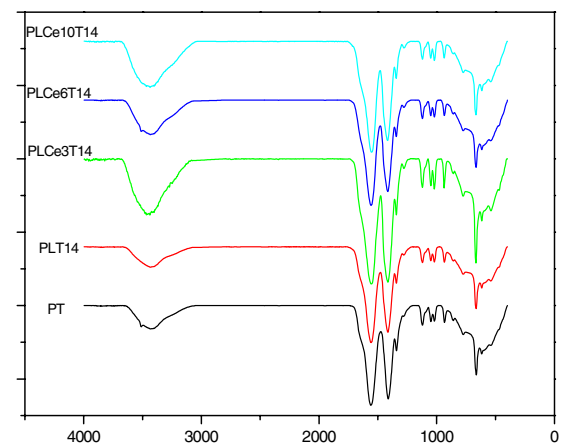

Figure 2. FTIR spectra of the raw powders corresponding to PT and $\mathrm{PLCe}_{x} \mathrm{~T} 14$.

On FTIR spectra of PT and PLCe ${ }_{x} \mathrm{~T} 14, \mathrm{x}=0 ; 0.03$, $0.06,0.10$, annealed at $700^{\circ} \mathrm{C}$ (Figure 3 ), one can observe the persistence of the band corresponding to the stretching of $\mathrm{OH}$ group, the disappearance of the other bands and the presence of a band around $550 \mathrm{~cm}^{-1}$.

Figure 4 shows XRD spectra corresponding to the sample with $\mathrm{x}=0.10$. The crystallization in the pseudo cubic phase, as confirmed by Raman spectra appearing below, begins at a relatively low temperature (about $400^{\circ} \mathrm{C}$ ), and no secondary phases are present except a peak relative to $\mathrm{PbO}$ added as an excess in the departing materials to compensate its volatilization during heat treatments. Introduction of $\mathrm{Ce}$ seems to lower the temperature of crystallization.

Figure 5 displays XRD patterns of PLCexT14 powders, $\mathrm{x}=0 ; 1 ; 3 ; 6 ; 10$, annealed at $700^{\circ} \mathrm{C}$; good crystallization in the pure perovskite structure was

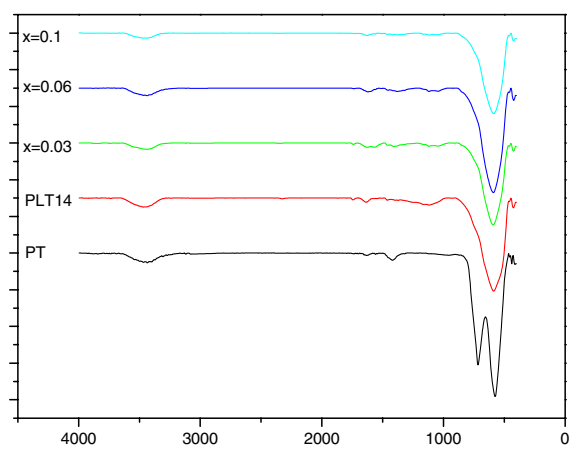

Figure 3. FTIR spectra of PT and PLCexT14 powders $(\mathrm{y}=0$, $0.03,0.06,0.10)$ annealed at $700^{\circ} \mathrm{C}(2 \mathrm{H})$.

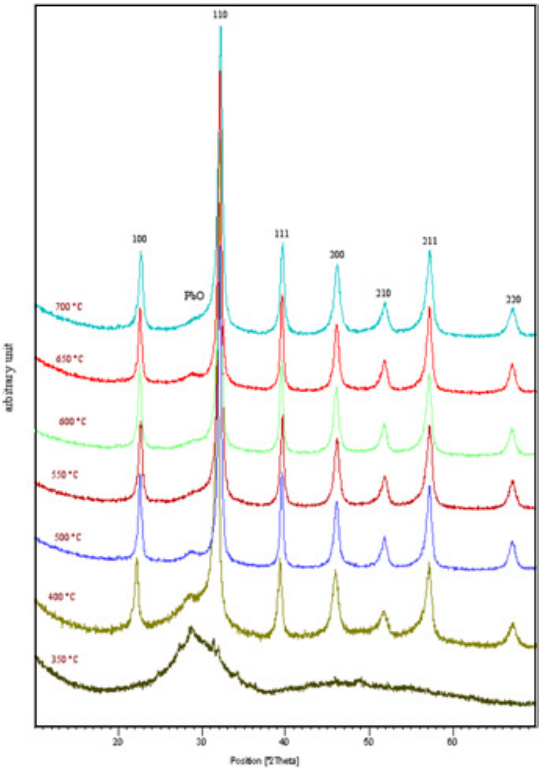

Figure 4. XRD spectra of $\mathrm{PLCe}_{x} \mathrm{~T} 14(\mathrm{x}=0.10)$ powder as functions of annealing temperature.

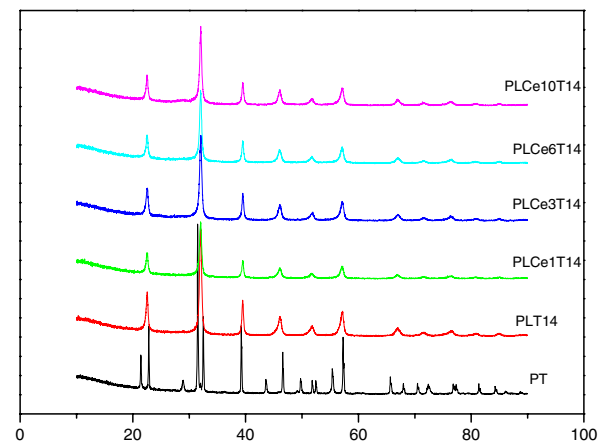

Figure 5. XRD spectra of PLCe ${ }_{x} \mathrm{~T} 14$ powders as functions of Ce content.

obtained for these compounds. The 101 and 110 peaks of PT pattern are separated clearly, while they merge in the case of the other samples to form one broadening peak. The structure transforms from tetragonal to pseudo cubic. Occurrence of the cubic phase has been reported for concentrations higher than $25 \%[5,6]$.

Raman spectroscopy constitutes a very useful tool for identification of phases. Figure 6 shows Raman spectra 


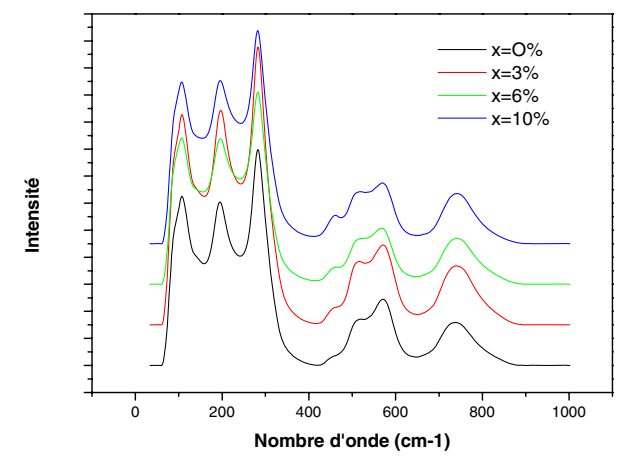

Figure 6. Raman spectra corresponding to $\mathrm{PLCe}_{x} \mathrm{~T} 14$ powders.

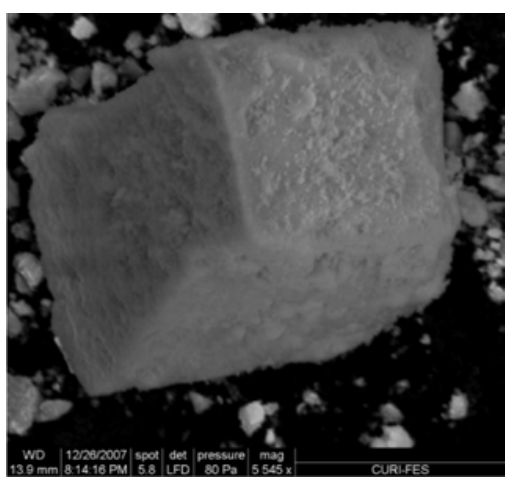

Figure 7. SEM micrographs of PLCe $\mathrm{P}_{x} \mathrm{~T} 14(\mathrm{x}=0.03)$ heat treated at $700^{\circ} \mathrm{C}(2 \mathrm{~h})$.

relative to PT and PLT14 samples heat treated at $700^{\circ} \mathrm{C}$, where the presence of the ten active phonons modes appearing on PT spectrum implies that of the tetragonal phase (Fig. 6). Distortion of the tetragonal structure with incorporation of La is revealed by a decrease of intensity of the peaks, their shift toward low or high frequencies, and their broadening. However, active modes are still present (Fig. 6), which indicates that the structure is still pseudo cubic. Introduction of $\mathrm{Ce}$ does not influence significantly the spectrum corresponding to PLT14 as shown on Figure 6.

SEM micrographs of raw and annealed $\left(700^{\circ} \mathrm{C}\right)$ powders of PLCe $\mathrm{P}_{x} \mathrm{~T} 14$ are represented in figures 7, exhibits large blocks surrounded by very aggregated small particles of nanometric size resulting probably from La-doping. These blocks, with irregular forms, are also present in the samples doped with Ce.

Variations of the permittivity of $\mathrm{PLCe}_{x} \mathrm{~T} 14, \mathrm{x}=$ $0.03 ; 0.10$, are shown on figures 8 . Dielectric measurements performed on our samples annealed at $\mathrm{Ta}=1100^{\circ} \mathrm{C}$ during the annealing time $\mathrm{t}_{\mathrm{a}}=4 \mathrm{~h}$. Doping of $14 \%$ at. of $\mathrm{La}$ produces a decrease of $\mathrm{T}_{\mathrm{c}}$ from $490^{\circ} \mathrm{C}\left(\mathrm{PbTiO}_{3}\right)$ to $290^{\circ} \mathrm{C}$ which is in good agreement with that reported by Tickoo $[1,7]$. The change in Curie temperature $\left(\mathrm{T}_{\mathrm{c}}\right)$ value with La addition results from the decrease of the tetragonality of the perovskite structure $[8,9]$.

The transition temperature from ferroelectric (FE) phase to paraelectric (PE) phase, corresponding to the maximum of the permittivity $\varepsilon_{\mathrm{r}}$ (Fig. 8). The FE to PE transition is relatively diffuse for the sample PLT14. This transition becomes sharper with increasing Ce content, and

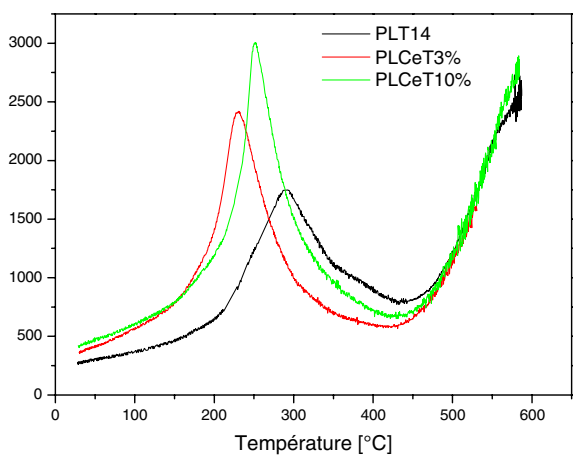

Figure 8. The permittivity behaviour, at the frequency $100 \mathrm{~Hz}$, of PLT14, PLCe ${ }_{x}$ T14 $(\mathrm{x}=0.03, \mathrm{x}=0.1)$.

Table 1. Values of $\varepsilon_{\mathrm{r}}$ and $\mathrm{T}_{\mathrm{c}}$ of PLCe $\mathrm{T}_{x} \mathrm{~T}$ ceramics, $\mathrm{x}=0,0.03$, 0.06 , and 0.1 , at frequency of $100 \mathrm{~Hz}$.

\begin{tabular}{ccc}
\hline $\mathrm{x}(\% \mathrm{Ce})$ & $\varepsilon_{\mathrm{r}}$ & $\mathrm{T}_{\mathrm{c}}\left({ }^{\circ} \mathrm{C}\right)$ \\
\hline 0 & 1740 & 290 \\
0.03 & 2418 & 230 \\
0.06 & 2600 & 254 \\
0.1 & 3006 & 251 \\
\hline
\end{tabular}

one observes an increase in the value of the maximum of the permittivity. Moreover, the temperature $\left(\mathrm{T}_{\mathrm{c}}\right)$ of the maximum of the permittivity is firstly lowered for the sample with $\mathrm{x}=0.03$, before a slight increase for $\mathrm{x}=$ 0.10. (Table 1).

\section{CONCLUSIONS}

$\mathrm{PbTiO}_{3}$ (PT) sol gel processed powders doped with lanthanum (PLT14) and cerium (PLCe $\mathrm{P}_{x} 14, \mathrm{x}=0.01$, $0.03,0.06,0.10)$ were characterized by XRD, SEM, FTIR and Raman spectroscopy. Incorporation of $\mathrm{Ce}$ (concentrations less or equal to $10 \%)$ in $(\mathrm{Pb}, \mathrm{La}) \mathrm{TiO} 3$ has been shown to lower the temperature of crystallization of the samples, and spectra were free of secondary phases apart $\mathrm{PbO}$ as it was added in excess in the departing materials to compensate its volatilization during heat treatments. SEM micrographs of the samples annealed at $700^{\circ} \mathrm{C}$ showed the presence of blocks of irregular form. Dielectric measurements showed that $\mathrm{Ce}$ reduces the diffuseness character of the ferroelectric to paraelectric transition, and to increase the permittivity.

\section{References}

[1] Y. Guaaybess, M. Moussetad, A. Elmesbahi, S. Sayouri, M. Maanan, R. Adhiri, L. Hajji, O. Azaroual. Phys-Chem. News, 53, P. 34-38 (2010).

[2] A. Elmesbahi, A. Khebeche, S. Sayouri, J. Catal. Mat. Env, 11, P. 51-54 (2003).

[3] Y. Guaaybess, M. Moussetad, A. Elmesbahi, S. Sayouri, M. Maanan, R. Adhiri, J. Catal. Mat.Env, Vol. VIII (2009). 
[4] M. Yoshimura, J. Mater. Res. 13, P.796, (1998)

[5] K. Iijima, R. Takayama, Y. Tomita, I. Ueda, J. Appl. Phys. 2914, 60 (1986).

[6] S. Chopraa, S. Sharma, T.C. Goel, R. G. Mendiratta, Applied Surface Science, 321, 327, 236 (2004).
[7] R. Tickoo, R. P. Tandon, N.C. Mehra, P. N. Kotru, Materials Science and Engineering, B94 (2002) 1-7.

[8] T. Yamamoto, H. Igarashi, K. Okazaki, J. Am. Ceram. Soc., 66 (5) (1983) 363.

[9] X. Dai, Z. Xu, D. Viehland, J. Appl. Phys., 79 (2) (1996) 1021-1026. 